\title{
A EVOLUÇÃO DA QUALIDADE E OS EFEITOS SOBRE A PRODUTIVIDADE DA LAMINAÇÃO A FRIO USIMINAS - USINA DE CUBATÃO*
}

\section{Resumo}

Fabio Tavares Chamonge ${ }^{1}$ Karl Kristian Bagger ${ }^{2}$ Vitor Caio de Almeida ${ }^{3}$

Este trabalho visa mostrar os principais benefícios alcançados na qualidade dos produtos e a evolução da produtividade nas linhas de produção da Laminação a Frio com a estabilização operacional da nova Decapagem. Os recentes investimentos na modernização tecnológica, com a aquisição e implementação da nova Decapagem com os recursos modernos de controle e automação permitiu que houvesse uma evolução significativa da qualidade dos produtos, eliminando o desvio, reduzindo o descarte e melhorando a produtividade ao longo do processo de fabricação. Com inicio de funcionamento da nova Decapagem possibilitou processar bobinas com maior peso, maior flexibilidade na formação de bobinas soldadas e menores descartes por qualidade, estes fatores afetaram positivamente o peso médio na saída da Decapagem. A melhoria do material processado na nova linha proporcionou elevação da produtividade do Laminador de tiras a frio, considerando os aspectos: oleamento, planicidade, peso de bobina, solda e isenção de manchas e defeitos superficiais. $O$ processo de Encruamento também foi beneficiado com peso de bobina e melhoria da forma do material. O produto final e os processos de acabamento também tiveram impactos positivos dos resultados obtidos na Decapagem 3.

Palavras-chave: Decapagem; Produtividade; Qualidade.

\section{THE EVOLUTION OF THE QUALITY AND THE EFFECTS ON PRODUCTIVITY ON COLD MILL PLANT AT USIMINAS CUBATÃO}

\section{Abstract}

This paper aims to show the main benefits achieved on Quality of products and evolution of the productivity on the cold mill production line with the operational stabilizing of the New Pickling Line in Cubatão Plant. The recente investments in technological updating with the aquisiting and implementing the modern Pickling Line with the modern features of control and automation, allows o reach significant evolution in the production processes of the Cold Roll Plant.

Keywords: Pickling line; Productivity; Quality.

1 Metalurgista, CQE, CQA, Gerente Geral da Laminação a Frio da Usiminas Cubatão.

2 Engenheiro Metalurgista FEl, Especialização em Siderurgia USP, Professor Universitário, Gerente Técnico da Laminação a Frio, Usiminas Cubatão.

3 Engenheiro Elétrico, Administrador de Empresa, Especialização em Automação Industrial FEl, Professor Universitário, Engenheiro de Processo Sênior do Suporte Técnico da Laminação a Frio da Usiminas Cubatão. 


\section{INTRODUÇÃO}

O mercado mundial de aços planos após 2005 passou a ser extremamente competitivo com ofertas superiores a demanda exigindo a estratégias para manter a participação o mercado.

Os requisitos são por materiais com alto grau de qualidade, isenção de descontinuidades e homogeneidade superficial, elevadas propriedades mecânicas e pequenas dispersões dimensionais.

Com a finalidade de atender estes requisitos e garantir a sua participação no mercado a Usiminas realizou investimento na sua linha de produção de Laminados a Quente em Cubatão.

Foi adquirida uma série de novos equipamentos;

Um novo Laminador de Tiras a Quente,

Laminador de Acabamento,

Linha Divisora e

Uma nova linha de Decapagem.

A nova Decapagem, o estado da arte em tecnologia, foi adquirida para processar principalmente materiais para estampagem, os aços HSLA e, especialmente os aços para aplicação em rodas, peças críticas automotivas e outras aplicações de extremo rigor.

\section{DESENVOLVIMENTO}

\subsection{Características do Equipamento}

A especificação sumária conta com a seguinte configuração visto na Tabela 1 , Figura 1, e um esquemático Figura 2:

$\checkmark$ Máquina de solda a laser;

$\checkmark$ Desempenadeira sob tensão;

$\checkmark$ Decapagem por turbulência em tanques rasos na seção de processo;

$\checkmark$ Estação de aparamento lateral com troca rápida de navalhas;

$\checkmark$ Medição de espessura por raio gama,

$\checkmark$ Inspeção de qualidade superficial automática;

$\checkmark$ Oleadeira eletrostática;

$\checkmark$ Identificação e cintamento automática das bobinas.

$\checkmark$ Balanças

$\checkmark$ Modelo matemático e elevado nível de controle e automação no processo.

Junto com a Decapagem, foram adquiridas e instaladas também duas plantas de novas Regeneração de Ácido (ARP) do tipo leito fluidizado, com capacidade de 6000 $\mathrm{m}^{3} / \mathrm{h}$ cada e um alto índice de automação, com um sistema de tratamento de gases para obtenção de baixo valores de emissão atmosférica. 
Tabela 1 - Principais características da linha

\begin{tabular}{|l|c|}
\hline Fabricante & Andritz Metals (Áustria) \\
\hline Capacidade nominal & $1,7 \mathrm{Mt} / \mathrm{ano}$ \\
\hline Produtividade máxima & $500 \mathrm{t} / \mathrm{h}$ \\
\hline Velocidade máxima & 02 \\
\hline Desenroladeiras & $240 \mathrm{mpm}$ (centro) e $300 \mathrm{mpm}$ (saída) \\
\hline Capacidade de acumulação & $500 \mathrm{~m}$ (entrada) e $400 \mathrm{~m}$ (saída) \\
\hline Tanques de processo & 04 tanques de 28 metros \\
\hline Enroladeiras & 02 \\
\hline Comprimento da linha & $250 \mathrm{~m}$ \\
\hline Diâmetro interno da bobina & Entrada: 660 ou $762 \mathrm{~mm}$ \\
& Saída: 610 ou $762 \mathrm{~mm}$ \\
\hline Diâmetro externo & Entrada: 1000 a $2.100 \mathrm{~mm}$ \\
& Saída: 800 a $2.100 \mathrm{~mm}$ \\
\hline Peso máximo & 35 toneladas \\
\hline
\end{tabular}

A seguir uma vista ao longo do sentido do processo.

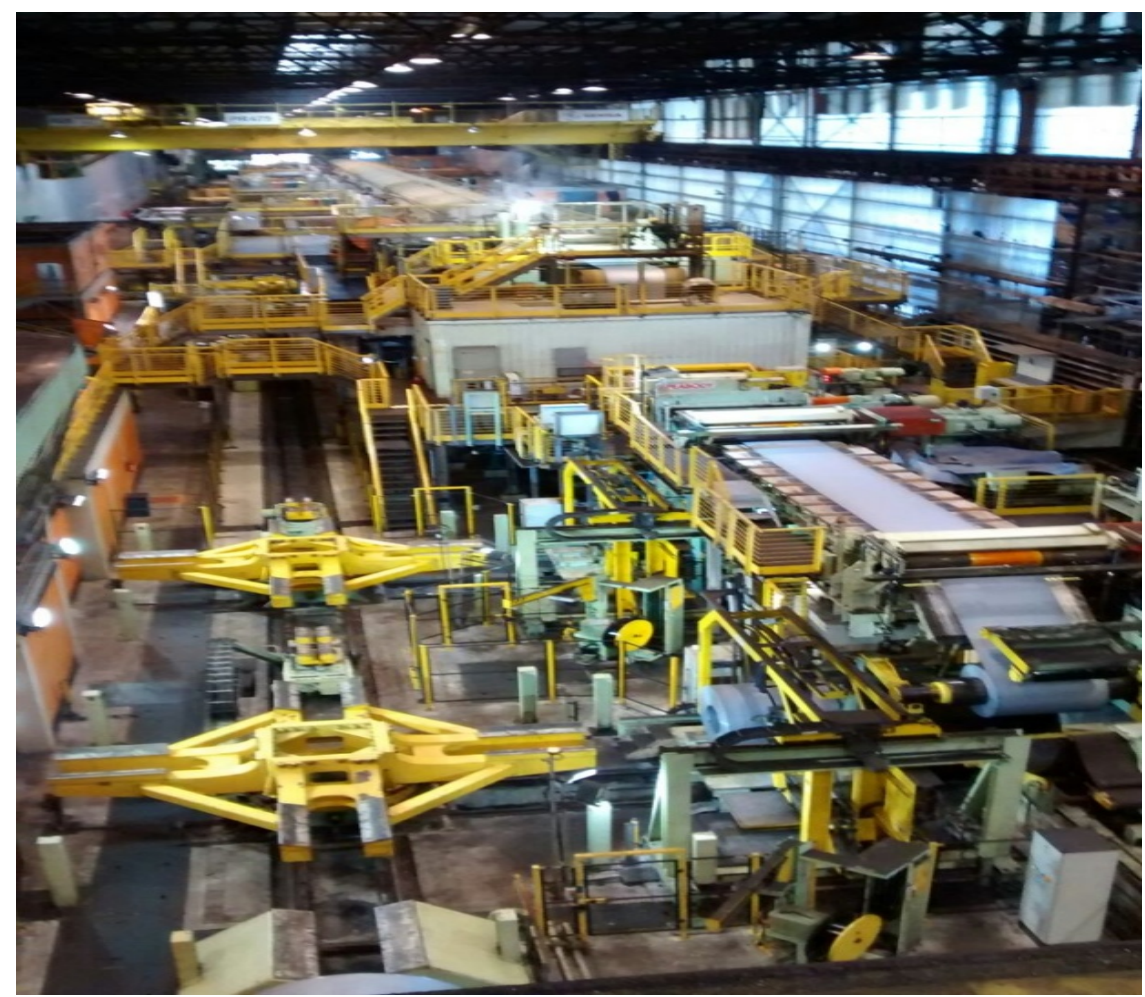

Figura 1 - Nova linha de Decapagem da Usiminas

Configuração da nova linha de Decapagem. 


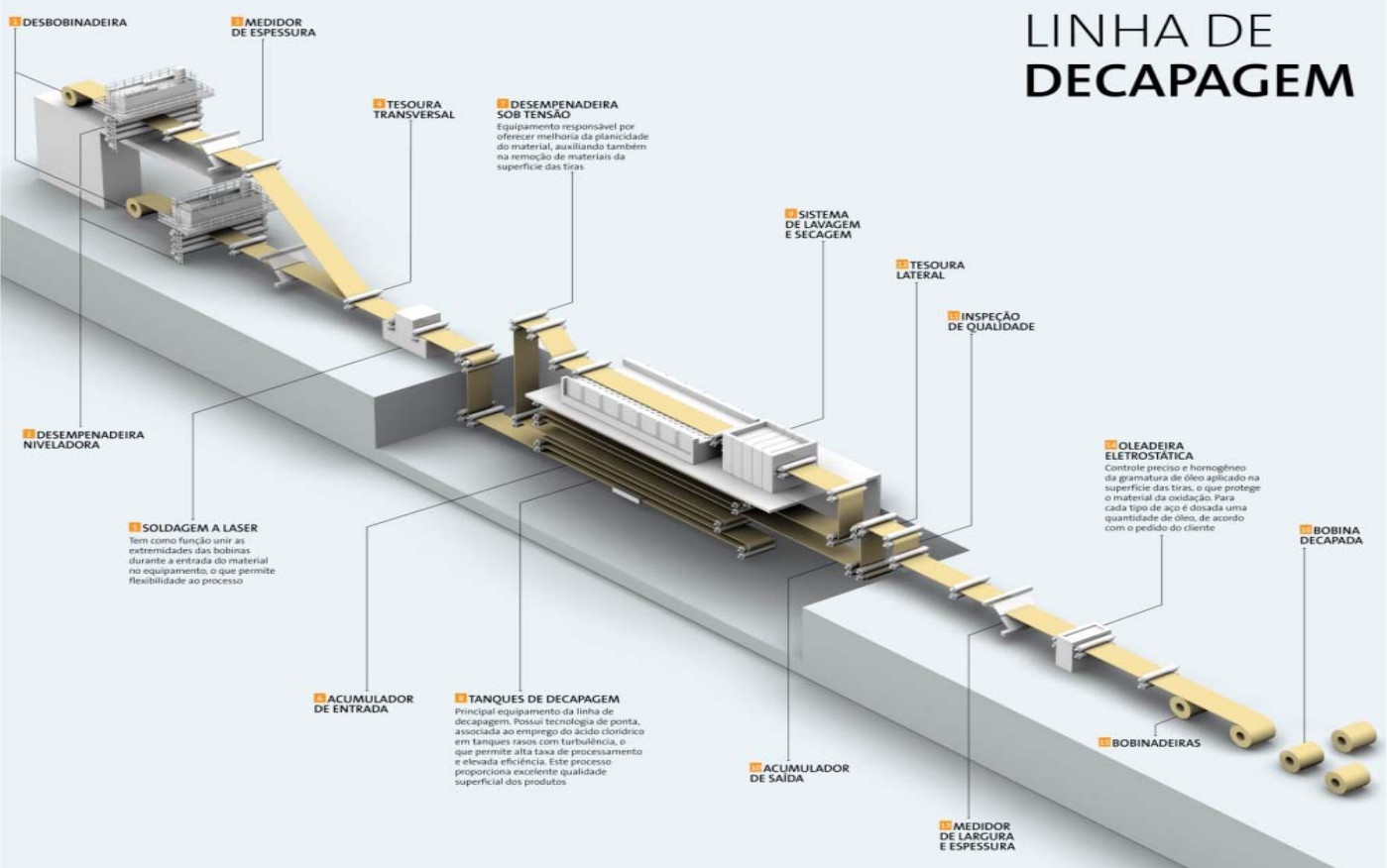

Figura 2 - Nova linha de Decapagem

\subsection{Características do Produto}

Os produtos especificados para produção na Decapagem da Usiminas possuem como principais características:

a. Dimensional; uma ampla faixa de espessura atendendo a materiais com espessura fina de 1,20 mm e atingindo extremos de $6,50 \mathrm{~mm}$.

$\mathrm{Na}$ largura atendendo dimensões de $600 \mathrm{~mm}$ até o máximo de $1800 \mathrm{~mm}$ ultra largo.

Quando solicitado, o aparamento de borda tem uma elevada precisão e isenção de imperfeições devido ao sistema de aparamento de ajustagem automático.

b. Peso elevado; flexibilidade para atender pesos de acordo com a melhor ocupação do transporte bem como os pesos solicitados pelos clientes.

c. Bobinamento preciso; bobinamento sem defeito de telescopia entre espiras e com uma flexibilidade de produção de bobinas até dois diâmetros internos na saída.

d. Controle do oleamento; devido o sistema de oleamento eletrostático que atua automaticamente através de comando interlocados com a especificação do pedido, obtém-se a gramatura especificada pelo cliente que pode ser no mínimo $0,30 \mathrm{~g} / \mathrm{m}^{2}$.

e. Região da solda; elevada precisão e perdas mínimas, nas bobinas que eventualmente forem soldadas devido a sua maquina a laser de ultima geração.

f. Garantia de isenção de defeitos; devido ao sistema de controle automático de processo que evita ocorrência de manchas de secagem, excesso de decapagem e falta de decapagem.

g. Qualidade com confiabilidade; a tira passa verticalmente na ampla cabine de inspeção facilitando e fornecendo todas as condições ao inspetor realizar a inspeção visual nas duas faces e bem como as conferencia nas regiões 
indicadas pelo sistema de inspeção automática e realizar a frequência de checagem estabelecido nos mais rigorosos padrões.

As dimensões são checadas na entrada do processo através da confrontação do físico com os valores dos processos anteriores e a especificação do cliente tanto na largura como na espessura.

h. Complexidade dos produtos; o projeto da linha permite processar materiais com alta complexidade e flexibilidade de produção. Gerando produtos de alta, media e baixa resistência, HSLA, IF, materiais de fins elétricos, Dual Phase, etc.

Isto e possível por causa do modelo matemático que determina os parâmetros das variáveis e sistemas de compensação de concentração aquecimento dos tanques permitindo ajustes precisos.

Na Figura 3 verificamos o mix de produção da Decapagem.

Tabela 2 - Características do produtos

\begin{tabular}{|l|c|}
\hline Espessura & 1,2 a $6,5 \mathrm{~mm}$ \\
\hline Largura & 600 a $1.800 \mathrm{~mm}$ \\
\hline Peso máximo & 35 toneladas \\
\hline Diâmetro interno & $\begin{array}{c}\text { Entrada: } 660 \text { ou } 762 \mathrm{~mm} \\
\text { Saída: } 610 \text { ou } 762 \mathrm{~mm}\end{array}$ \\
\hline Diâmetro externo & $\begin{array}{c}\text { Entrada: } 1000 \text { a } 2.100 \mathrm{~mm} \\
\text { Saída: } 800 \text { a } 2.100 \mathrm{~mm}\end{array}$ \\
\hline Peso máximo & 35 toneladas \\
\hline
\end{tabular}

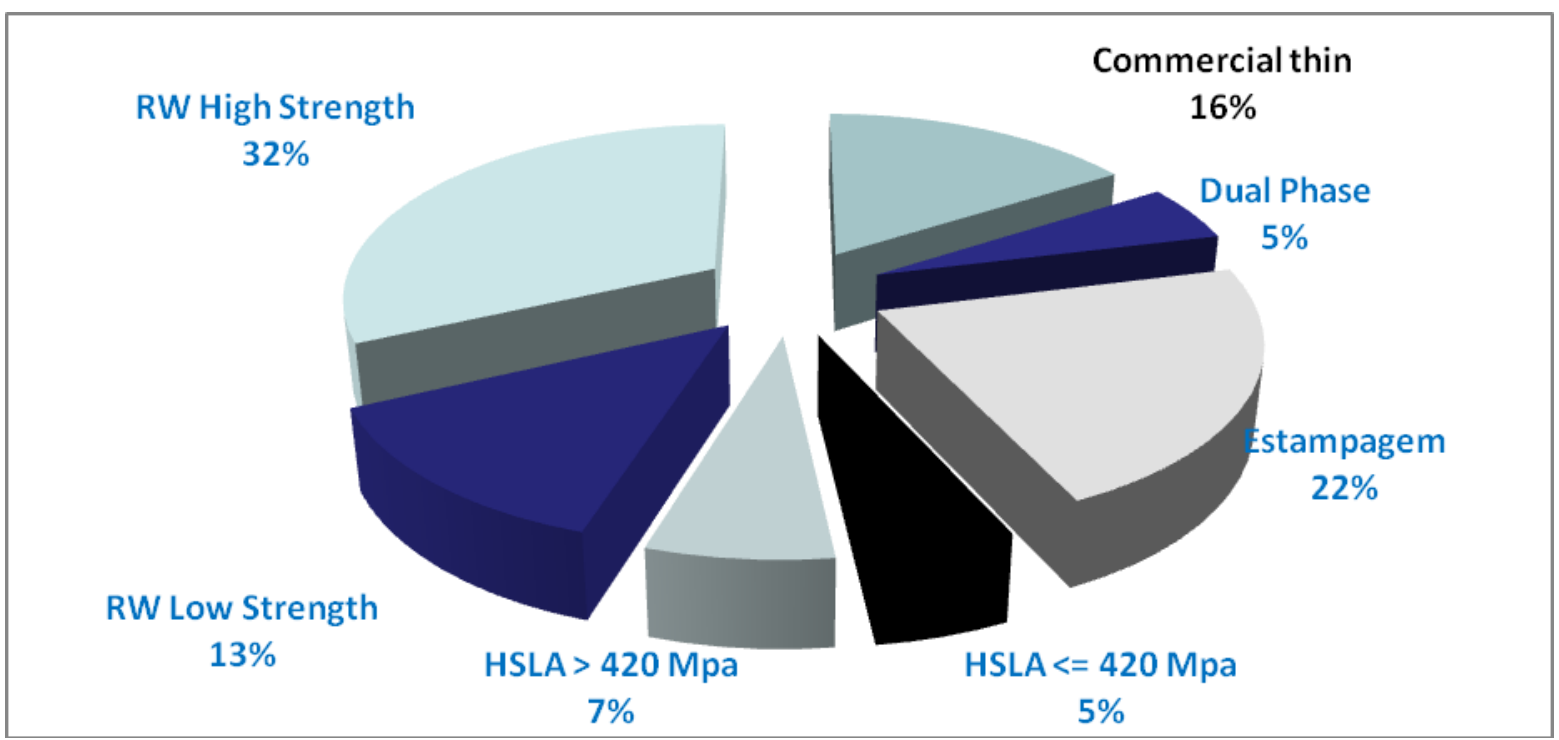

Figura 3 - Mix de produção da decapagem

\subsection{Produtividade}

A abordagem deste trabalho será os ganhos obtidos na linha de laminação a frio por consequência do bom desempenho da nova Decapagem.

A evolução do peso médio de bobina foi de $17,55 \mathrm{t}$ para $18,14 \mathrm{t}$, conforme mostrado na figura 4. 


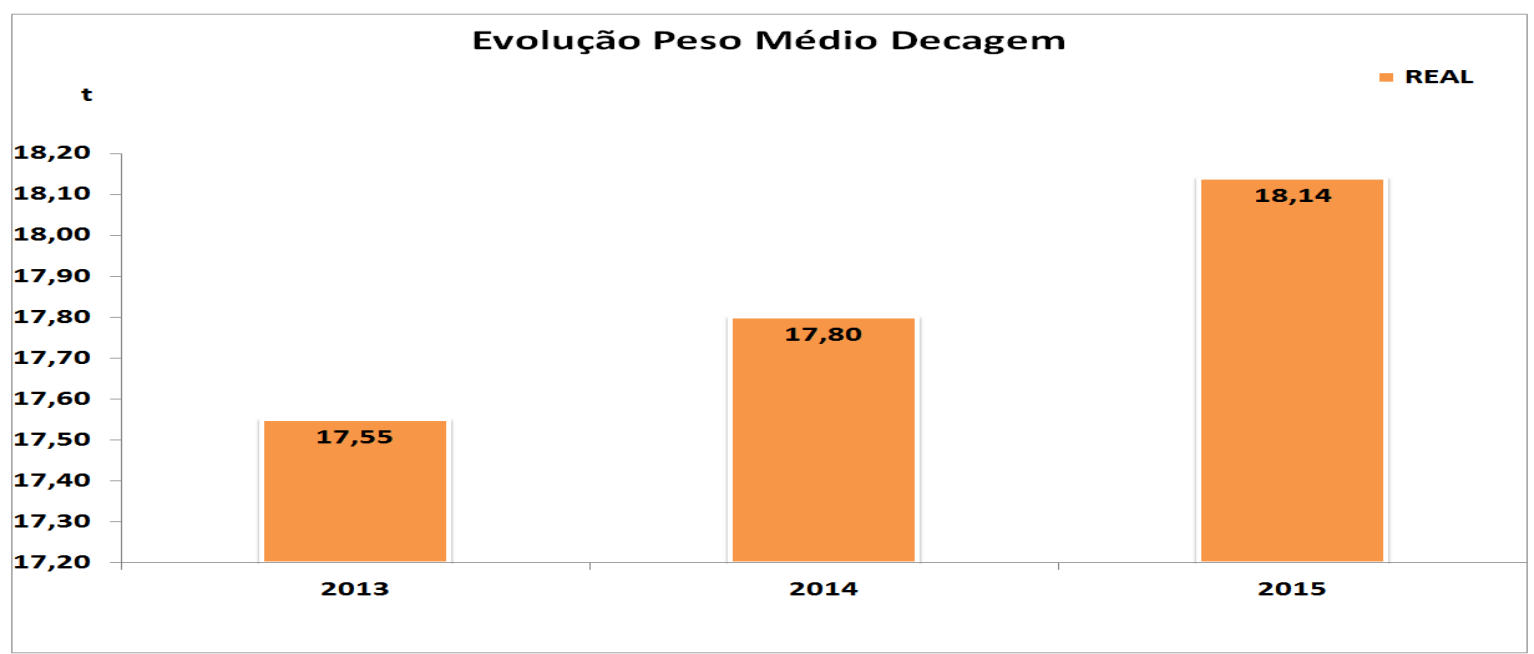

Figura 4 - Evolução do peso médio na Decapagem

Os resultados medidos de ganho serão a produtividade efetiva também conhecida como tonelagem horária das linhas posteriores da Decapagem. Estes resultados serão comparados aos valores médios dos anos anteriores a implantação da nova linha. Apenas lembrando que a produtividade efetiva é o quociente da produção pelo tempo utilizado.

Na Figura 5 observa-se que o aumento de produtividade do Laminador de Tiras a Frio atingindo $12,02 \%$ devido ao aumento do peso médio carregado, a melhor estabilidade do processo devido a isenção de defeitos, a isenção da solda e nas bobinas com solda uma confiabilidade maior, e forma do material melhor no que tange a planicidade.

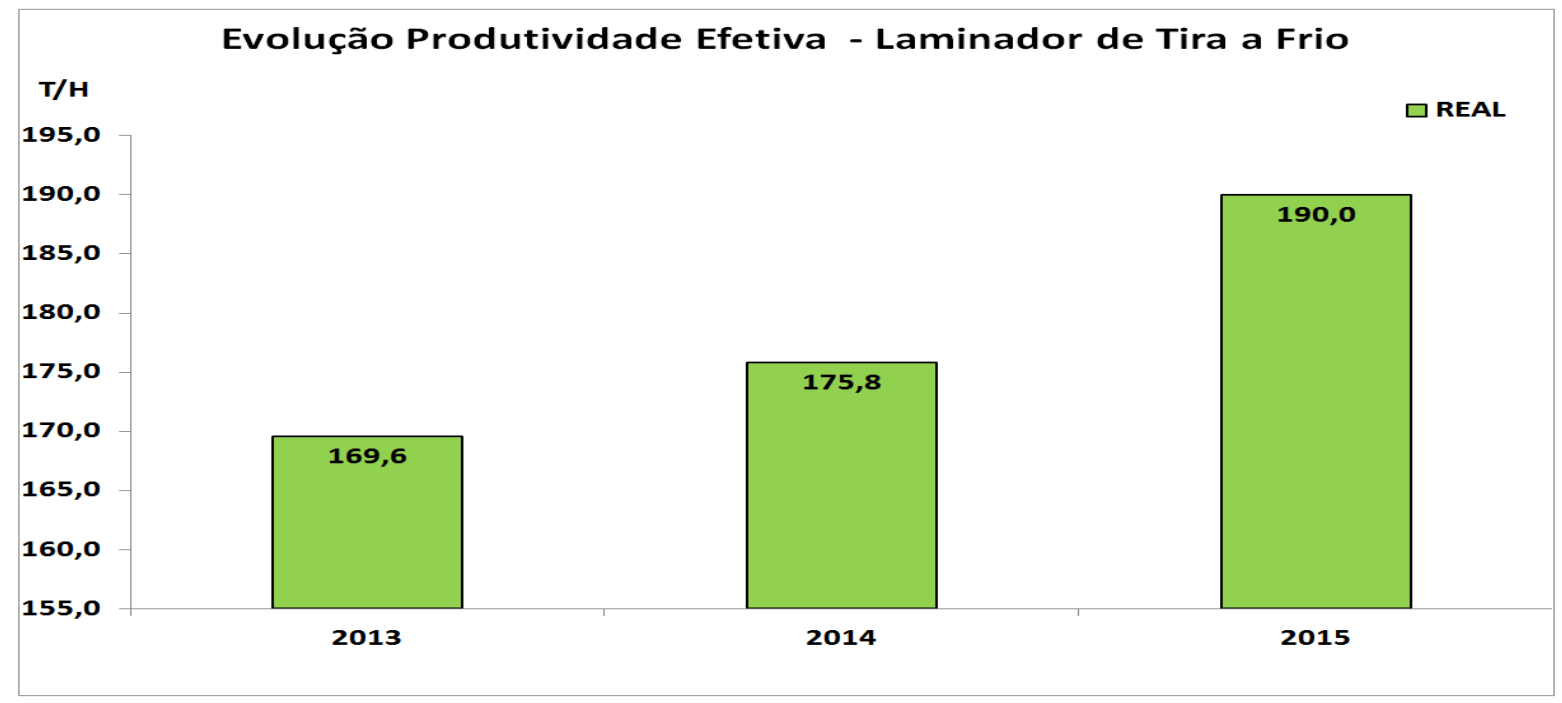

Figura 5 - Evolução da produtividade efetiva do laminador de tiras a frio

O gráfico da Figura 6 mostra a evolução do índice de ruptura de solda da decapagem no laminador de tiras a frio. 


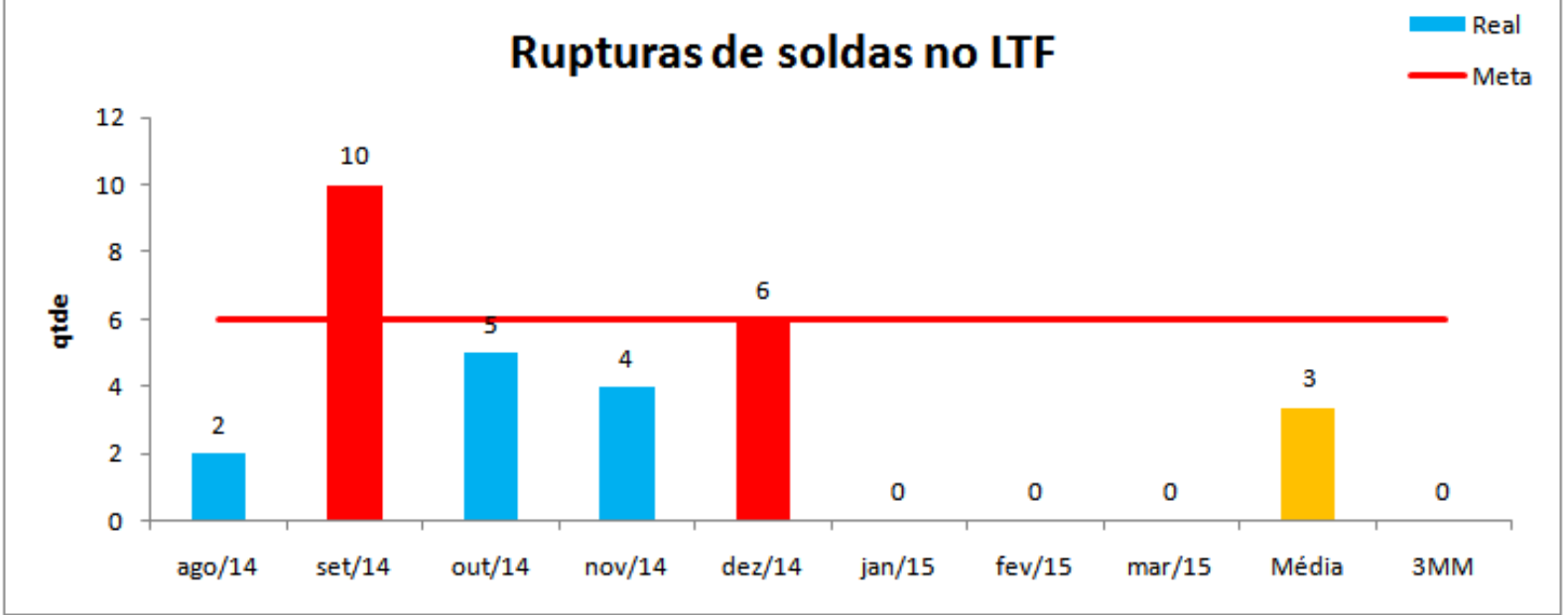

Figura 6 - Índice de ruptura de solda no laminador de tiras a frio

Os benefícios também foram constatados na linha de Encruamento, pelo aumento do peso médio e a melhora da qualidade do material, conforme mostrado no gráfico 5, onde a variação de 2013 á 2015 representou $14,84 \%$.

Melhorando assim sensivelmente as ocorrências de rupturas por colamento, ondulações, marcas ou defeitos no material oriundo dos processos anteriores. Os indicadores e sua evolução encontram-se a seguir no gráfico da Figura 7.

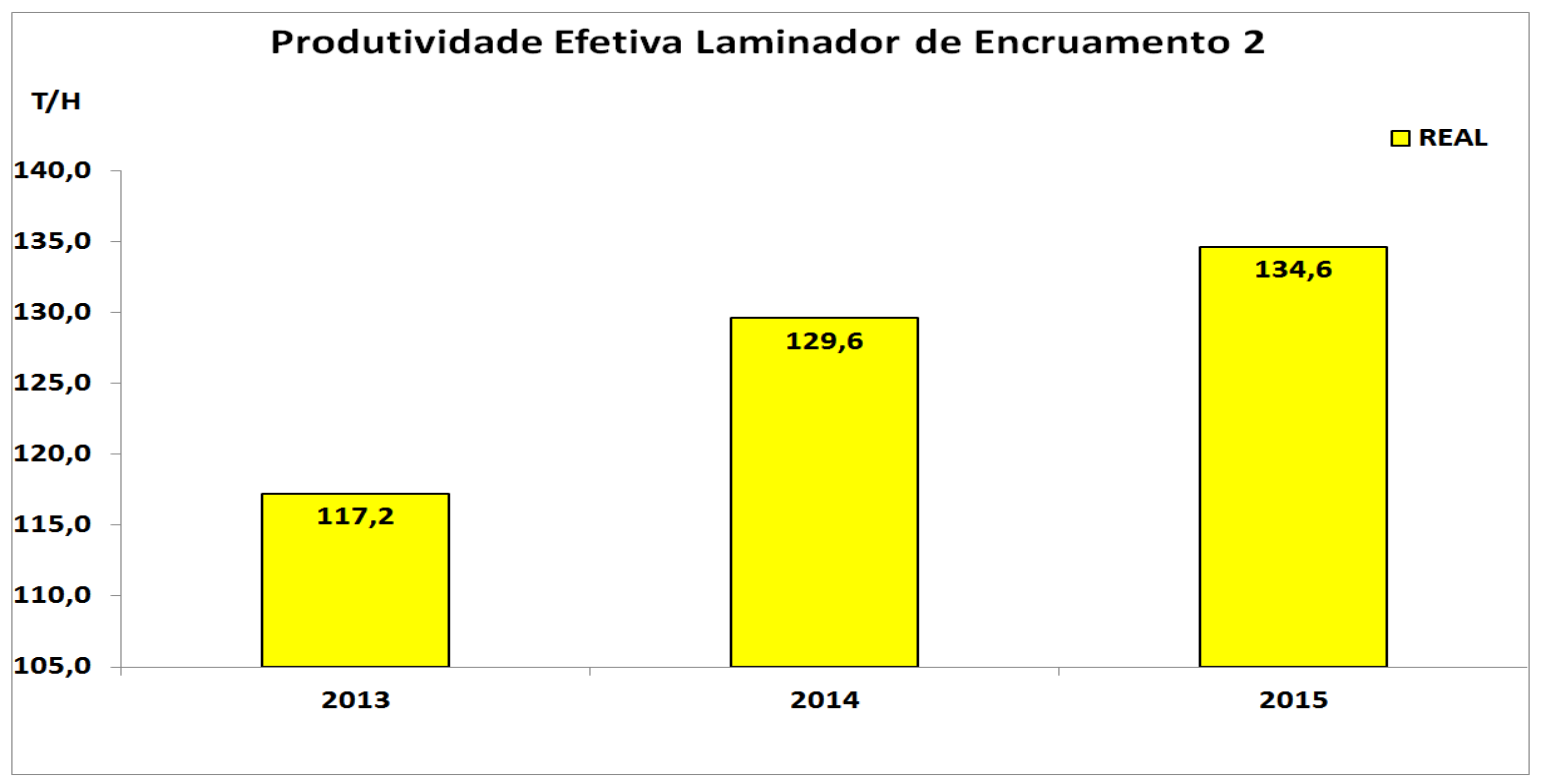

Figura 7 - Produtividade efetiva do laminador de Encruamento $n^{\circ} 2$

Nas linhas de Acabamento e Inspeção final, tanto na linha 1 como na linha 2 foram identificados ganhos apesar do enobrecimento do mix e por consequência maior rigor nos padrões. Na Linha Inspeção 1 obteve-se um incremento de 7,4 t/h cerca de $10 \%$ enquanto que na Linha de Inspeção 2, o acréscimo de 6,8 t/h cerca 14,1\%.

As Figuras 8 e 9 apresentam os dados referidos. 
Evolução Produtividade Efetiva - Linha de Inspeção 1

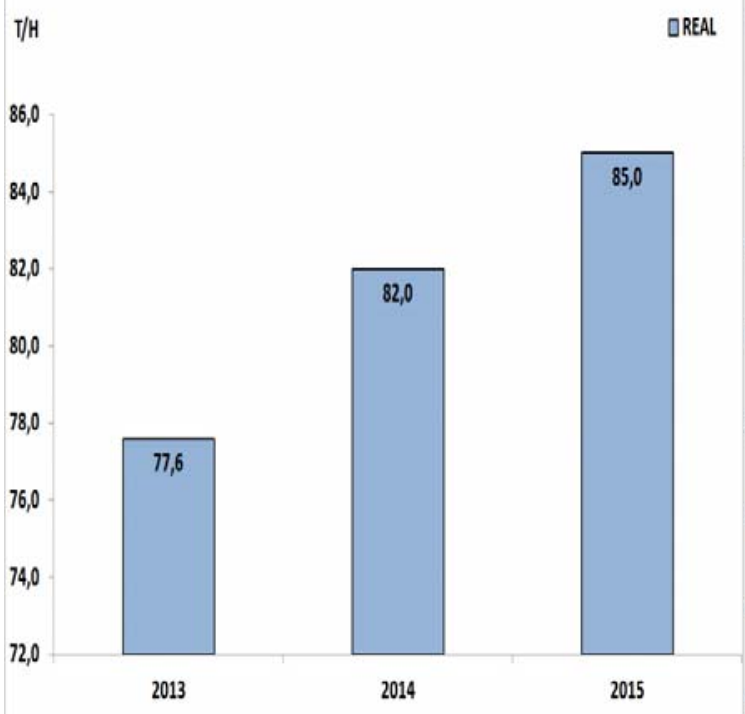

Figura 8 - Produtividade efetiva LI-1

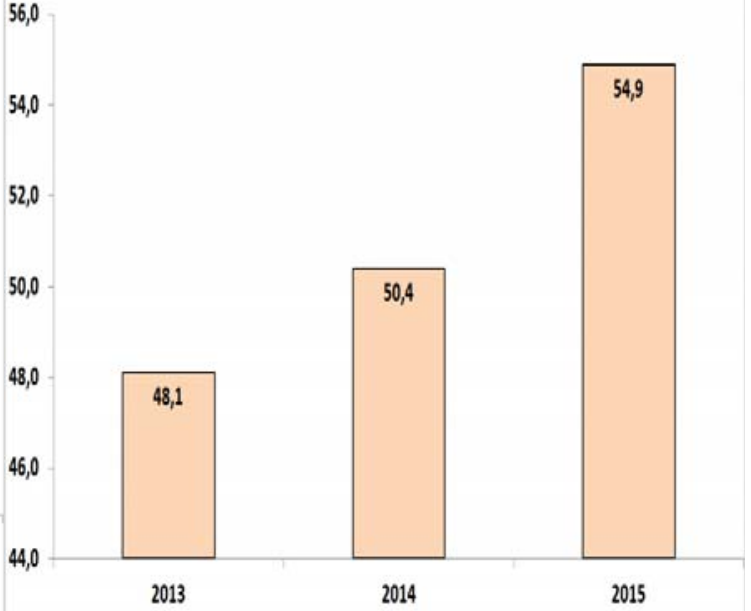

Figura 9 - Produtividade efetiva LI-2

O efeito do nível de qualidade do produto atinge diretamente a velocidade, as interrupções para descarte ou conferência de anomalias no produto com a regularidade o aumento foi sensível nestas linhas.

\subsection{Indicadores de qualidade}

O principal indicador de qualidade do processo é a Queda Qualitativa. Neste indicador as perdas por desclassificação, também chamadas de desvio ou índice de rejeição. É o indicador para medição da qualidade.

A Figura 10 mostra a redução de desvios por responsabilidade da Decapagem, com uma média de $0,24 \%$ para uma meta de $0,42 \%$.

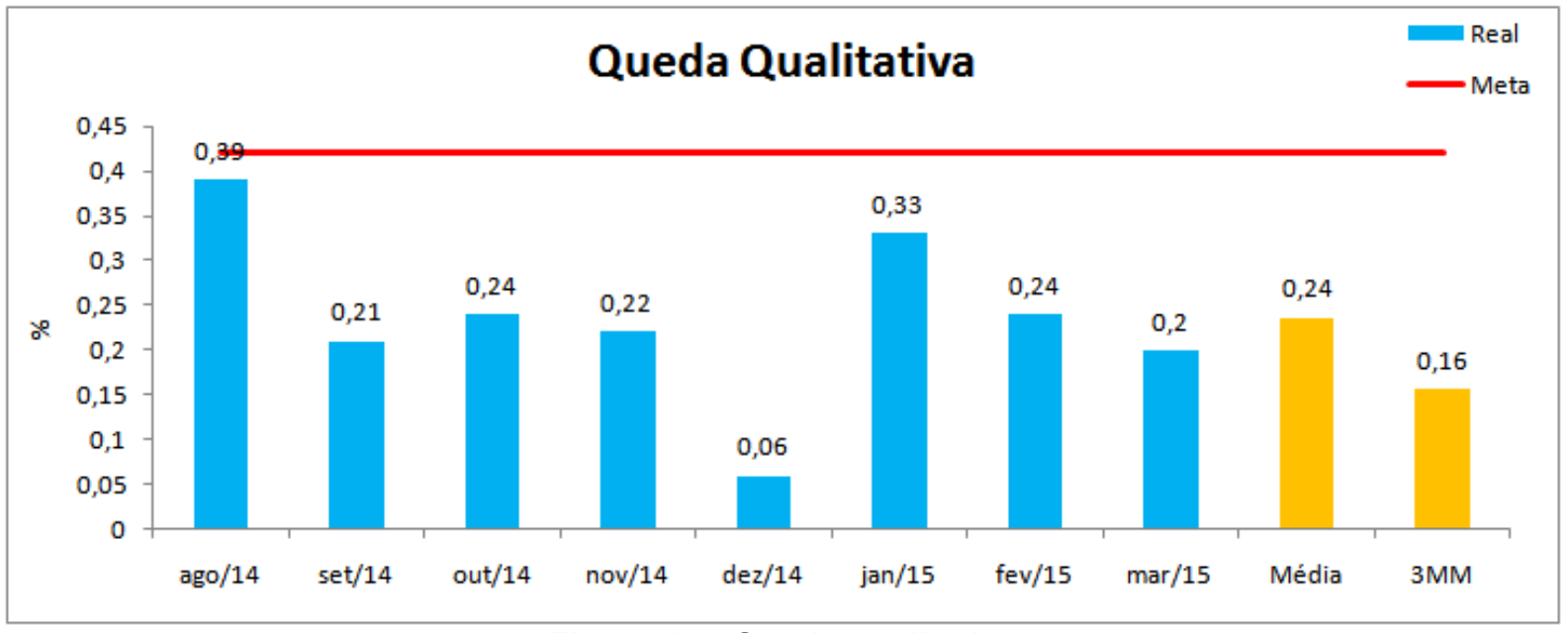

Figura 10 - Queda qualitativa

O Rendimento de Produto do material a frio é o indicador que mede as perdas de matéria prima no carregamento, ou seja, "rendimento de produto" é a diferença entre o peso do material carregado na linha de entrada da Decapagem e o peso do material inspecionado antes de ser enviado ao cliente. A contabilização de 
rendimento de produto são as perdas por defeitos, incluindo as perdas tecnológicas chamados de descarte ou corte. É um excelente indicador para a medição de qualidade que afeta diretamente o custo, pois representa o melhor aproveitamento da matéria prima no caso Bobina a Quente (BQ)

O gráfico da Figura 11 mostra o aumento no rendimento de produto.

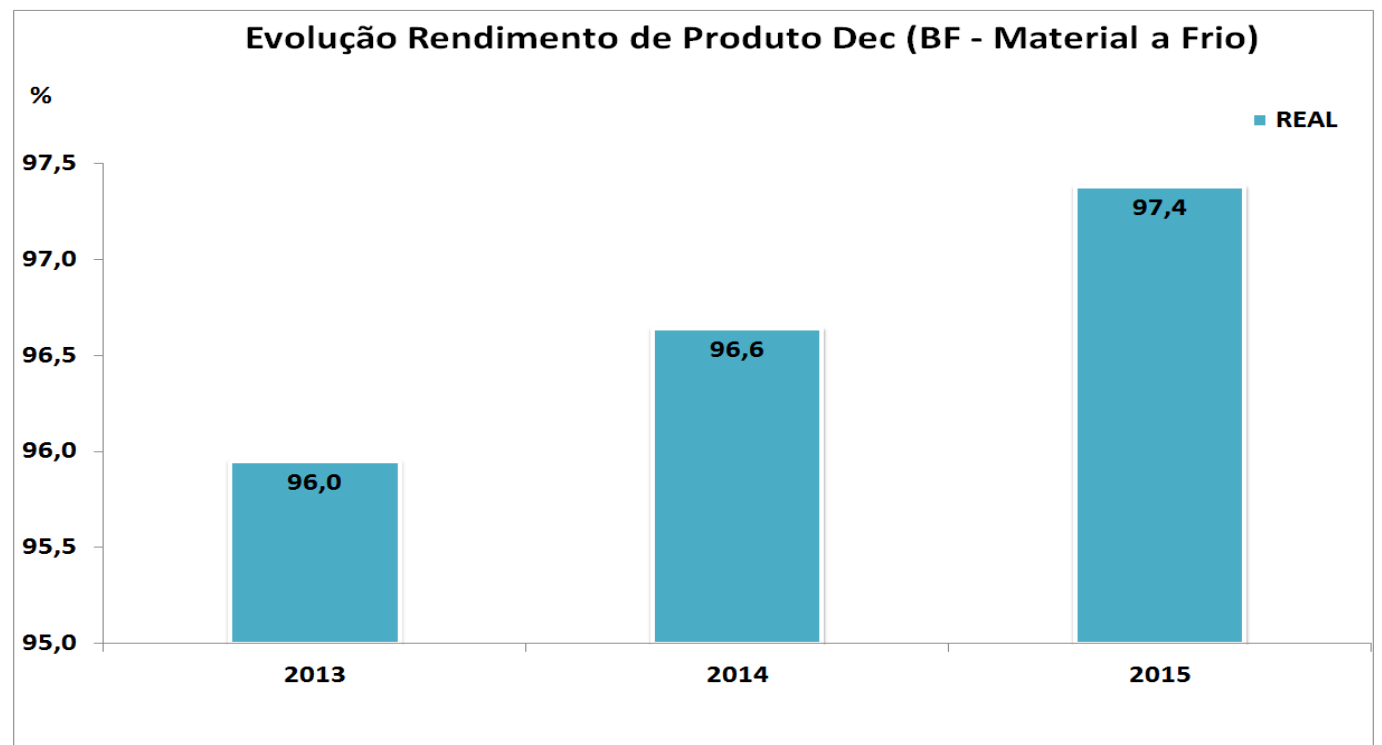

Figura 11 - Evolução do rendimento de produto do material a frio destinado ao LTF

A Figura 11 mostra que houve uma melhoria significativa no rendimento de produto (descartes) no material a frio, representando em média um ganho de $1,4 \%$ se compararmos os valores 2012 a 2015.

No rendimento global ou integrado da linha que considera todos os processos houve uma sensível evolução de 2,0 \% conforme observada na Figura 12.

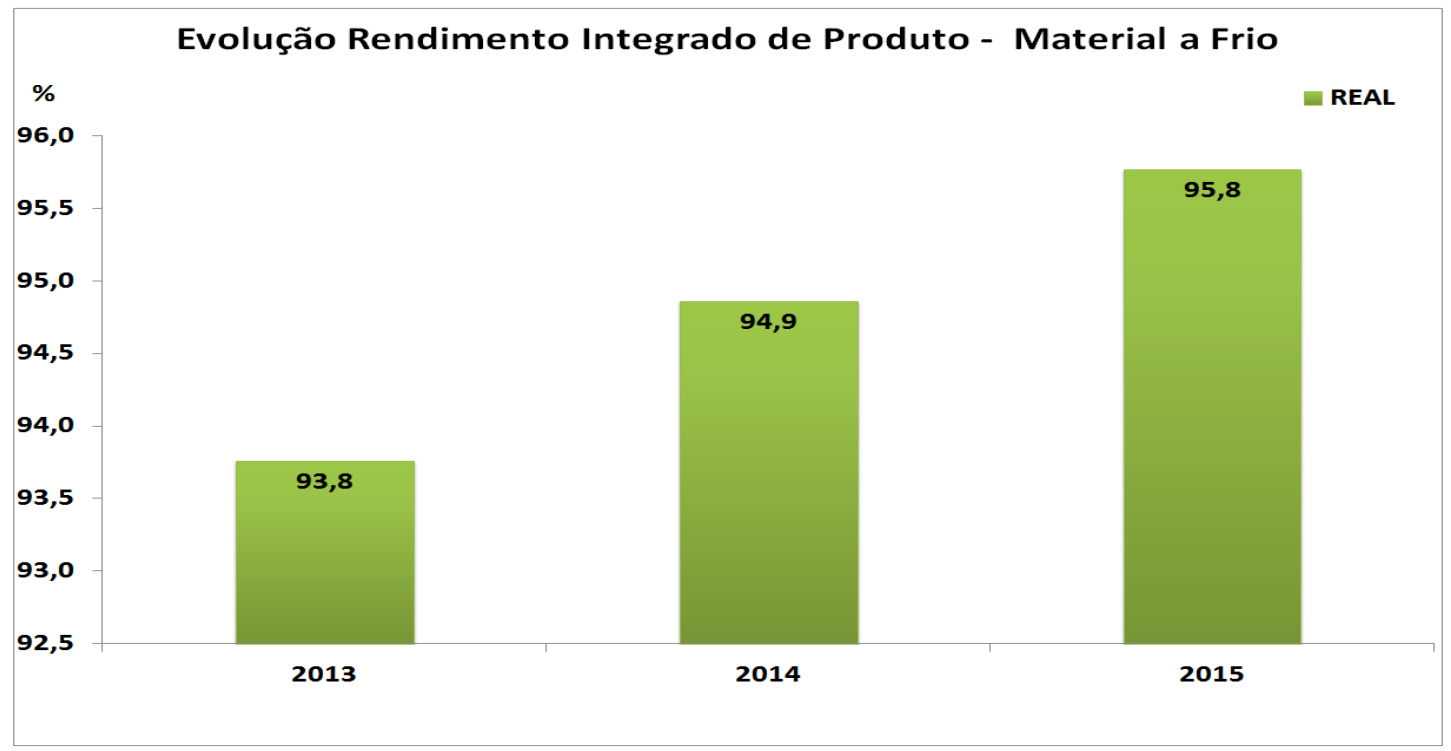

Figura 12 - Rendimento Material a Frio

No produto final da decapagem o Rendimento de Produto do material a quente, o conceito de perdas também é definido como o material sucatado ou descartado por não atender aos requisitos especificados além das perdas tecnológicas referentes às perdas por pontas, aparamento e no banho de processo. 
A Figura 13 mostra o aumento no rendimento de produto do material a quente (produto final BQD) houve uma evolução significativa no rendimento de produto (descartes) no material a quente, representando em média um ganho de $0,67 \%$ se compararmos os primeiros três meses de 2015 em relação a agosto de 2014 .

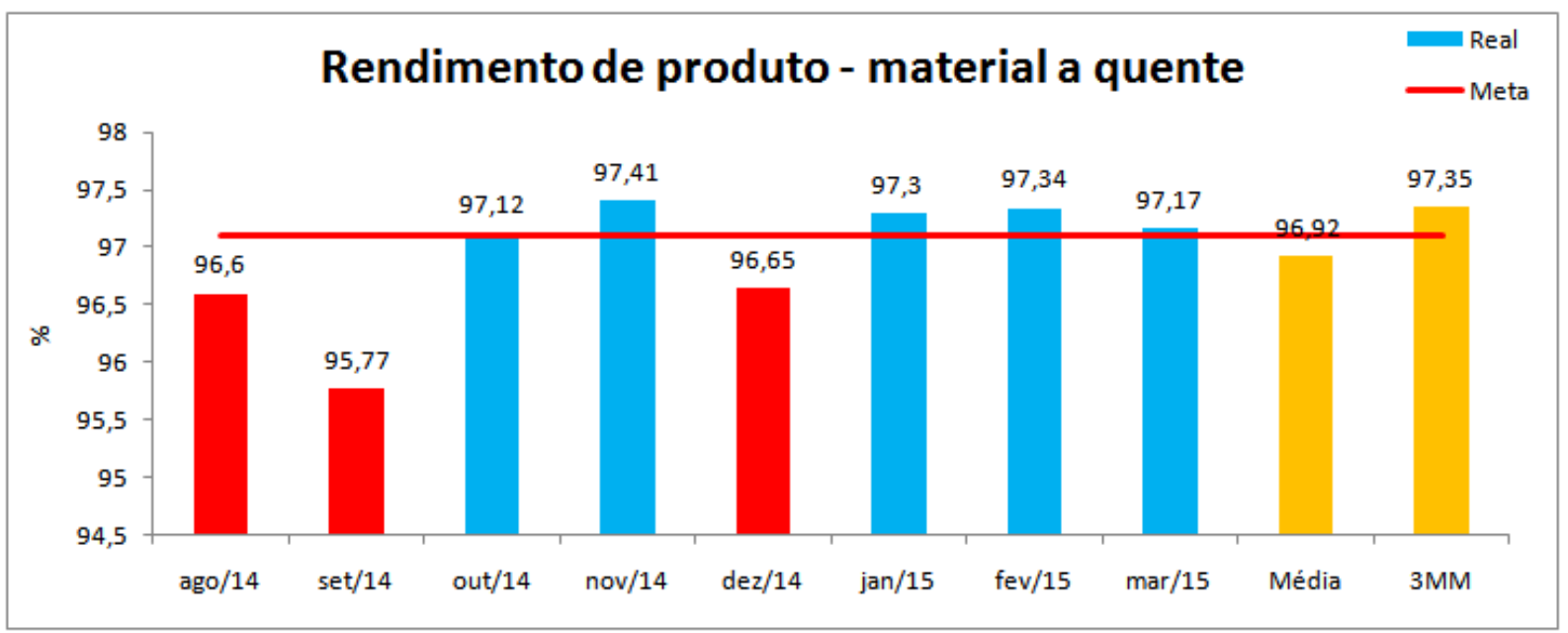

Figura 13 - Rendimento de produto de material a quente.

\section{COMENTÁRIOS FINAIS}

A nova linha de Decapagem da Usiminas após a sua partida, teste e estabilização operacional demonstra que seus resultados contribuem de forma consistente nos resultados da empresa:

$\checkmark$ Houve a ampliação do portifólio de seus produtos tanto nas dimensões como nas qualidades;

$\checkmark$ Os índices de qualidade evoluíram permitindo um melhor aproveitamento do material com reduções no down grade (quedas qualitativas) e perdas no sucateamento (descarte no rendimento) como comprovam os indicadores.

$\checkmark$ Os efeitos da melhoria agregada no processo de Decapagem resultaram em incrementos significativos na produtividade das linhas me toda planta de laminação a frio.

$\checkmark$ A melhoria introduzida no processo reduziu o nibvel de defeitos agregados ao longo dos processos subsequentes elevando o rendimento global da planta.

$\checkmark$ A moderna tecnologia agregada no equipamento permite avanços ainda maiores na qualidade, confiabilidade, flexibilidade e nos indicadores de qualidade e produtividade.

\section{REFERÊNCIAS}

1 ALMEIDA, V.C., BAGGER,K.K. Nova Decapagem da Usiminas Cubatão. In: Seminário de Laminação - Processos e Produtos Laminados e Revestidos, 47, 2010, Belo Horizonte. Minas Gerais, ABM, 2010. São Paulo: ABM, 2010.

2 BAGGER, K.K., ET AL. A Nova Linha de Decapagem da Usiminas. In: Seminário de Laminação - Processos e Produtos Laminados e Revestidos, 51, 2014, Foz do Iguaçu. Paraná, ABM, 2014. Paraná: ABM, 2014.

3 ANDRITZ METALS. Especificação Técnica da Nova Linha de Decapagem. São Paulo: 2012. 